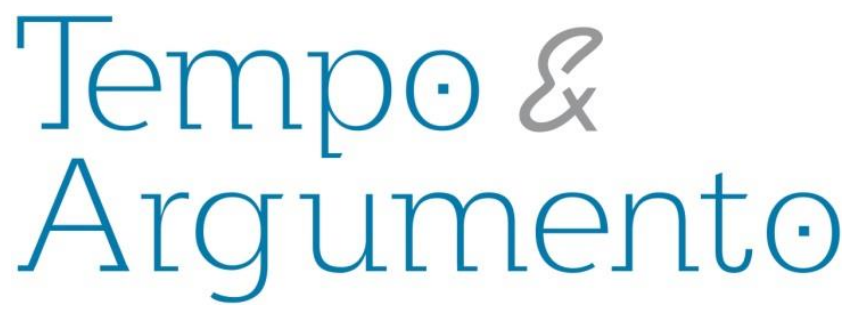

\title{
Bravas e insubmissas: mulheres e gênero na literatura memorialista do sertão norte-mineiro ${ }^{1}$
}

\section{Resumo}

Neste artigo, busco entender a construção de representações sobre mulheres e gênero no sertão norte-mineiro nas primeiras décadas do século $\mathrm{XX}$, a partir das memórias autobiográficas de Cyro dos Anjos, em A Menina do Sobrado, e de Darcy Ribeiro, no livro Confissões. Argumento que, apesar do patriarcalismo que governa as relações, os papéis de gênero, nessa região, não eram tão fixos, e as mulheres não estavam submetidas a um modelo de comportamento baseado no que podemos chamar de domesticidade burguesa, em que são valorizados certos aspectos, como fragilidade, passividade e submissão.

Palavras-chave: Mulheres. Minas Gerais. História. Gênero.
Cláudia de Jesus Maia

Doutora em História pela Universidade de Brasília ( UnB). Estágio Pós-Doutoral na Universidade Nova de Lisboa (UNL). Professora na Universidade Estadual de Montes Claros (UNIMONTES). Bolsista de produtividade da FAPEMIG. Montes Claros - MG - Brasil claudia.maia@unimontes.br

\section{Para citar este artigo:}

MAIA, Cláudia de Jesus. Bravas e insubmissas: mulheres e gênero na literatura memorialista do sertão norte-mineiro. Tempo e Argumento, Florianópolis, v. 10, n. 25, p. 358 - 384, jul./set. 2018.

\section{DOI: $10.5965 / 2175180310252018358$}

http://dx.doi.org/10.5965/2175180310252018358

\footnotetext{
${ }^{1}$ Esta pesquisa está sendo desenvolvida com o apoio financeiro da Fundação de Amparo à Pesquisa do Estado de Minas Gerais - FAPEMIG, e integra o projeto Gênero e insubmissão feminina no Norte de Minas.
} 


\title{
Brave and insubmissive: women and gender in the memorialist literature of the backwoods of the North of Minas Gerais
}

\begin{abstract}
In this paper, I seek to understand the construction of representations about women and gender in the backwoods of the North of Minas Gerais in the first decades of the twentieth century, from the autobiographical memoirs of Cyro dos Anjos, in A Menina do Sobrado, and Darcy Ribeiro's book, Confissões. Arguing that due to the patriarchy which rules relationships, gender roles, in this region, were not established among women and them weren't subjudge to a behavior pattern based in which we can call as bourgeois domesticity in which aspects as fragility, passivity and submission are valued.
\end{abstract}

Keywords: Women. Minas Gerais. History. Gender.

\section{Introdução}

Em suas viagens pelo sertão norte-mineiro em julho de 1817, o naturalista francês Auguste de Saint-Hilaire observou e registrou em sua "Viagem pelas províncias do Rio de Janeiro e Minas Gerais" que, durante todo o tempo em que esteve hospedado na fazenda Santo Elói, de propriedade do capitão Pedro Versiani ${ }^{2}$, a dona da casa não se mostrou; dela o viajante só pôde ver um "simpático vulto" através da porta entreaberta durante as refeições, concluindo que: "é mediante uma curiosidade desse tipo que as senhoras procuram compensar a escassa liberdade de que podem gozar" (SAINT-HILAIRE, 1975, p. 325, grifos meus).

\footnotetext{
${ }^{2}$ Bisavô materno do escritor Cyro dos Anjos, Pedro Versiani, natural de Luca, na Itália, e filho de João Antônio Maria Versiani, veio para o Brasil em meados do século XVII para ocupar o cargo de caixa da Real Extração de Diamantes no Tijuco. Segundo o memorialista Hermes de Paula (2007, p. 210), o "Capitão Pedro", como era conhecido, foi expulso do Tijuco por dar "braço forte ao pai em luta contra o Intendente Câmara”, por isso fundou a Fazenda Santo Elói (hoje município de Bocaiúva) em área que pertencia ao município do Serro, passando depois ao domínio do município de Montes Claros.
} 
Passados pouco mais de vinte anos, outro viajante europeu, o médico britânico George Gardner, também foi recebido em Santo Elói e, além dos elogios à administração da fazenda e à hospitalidade do anfitrião - assim como fizera o visitante anterior -, registrou ainda o descontentamento do capitão com as "irritantes" observações de SaintHilaire, que o haviam ofendido grandemente. Mas, ao contrário do viajante francês, Gardner observou que: "A mesma dama ainda vivia e eu a vi todo tempo que estive em sua casa: mas vinte e três anos haviam feito grande mudança no lindo rosto de que St. Hilaire tivera apenas uma visão fugitiva"; e completa: "suas filhas porém, agora crescidas, não eram menos acanhadas do que a mãe o fora nos dias da mocidade" (GARDNER, 1975, p. 197).

Um século depois, Cyro dos Anjos $^{3}$ também entraria na polêmica, saindo em defesa do Capitão Versiani, seu bisavô, ao explicar: foi o "acanhamento, provavelmente, que não deixou minha bisavó ir à presença do forasteiro", e não a "tirania" do marido (ANJOS, 1994, p. 91), homem culto, vanguardista e influente eleitor do Império.

Em estudo sobre o cotidiano feminino no Brasil do século XIX, a partir de relatos de viajantes ingleses e norte-americanos, Tânia Quintaneiro destaca que um dos aspectos observados por esses viajantes foi o costume, comum a todas as classes, de esconder as mulheres da vista dos forasteiros ${ }^{4}$.

\footnotetext{
${ }^{3}$ Cyro Versiani dos Anjos, jornalista, professor, cronista, romancista, ensaísta e memorialista, nasceu em Montes Claros - MG em 5 de outubro de 1906, e faleceu no Rio de Janeiro - RJ em 4 de agosto de 1994. Foi $013^{\circ}$ dos quatorze filhos do casal Antônio dos Anjos e Carlota Versiani dos Anjos. Fez o curso primário em Montes Claros e começou seus estudos secundários na Escola Normal da mesma cidade. Em fins de 1923, foi para Belo Horizonte, onde se formou em Direito em 1932. Exerceu vários cargos públicos importantes no Estado de Minas Gerais e no governo Federal, sobretudo durante o governo de Juscelino Kubitschek - JK; foi um dos fundadores da Universidade de Brasília - UnB, onde também atuou como professor, e da Faculdade de Filosofia da universidade Federal de Minas Gerais - UFMG. Foi eleito em 1969 para a Cadeira 24 da Academia Brasileira de Letras - ABL, sucedendo Manoel Bandeira. Disponível em: <http://www.academia.org.br/academicos/cyro-dos-anjos/biografia 2 .

${ }^{4}$ Para alguns viajantes, esse costume era mais típico das "classes médias" e seria característica das culturas ibéricas, herdada da prolongada ocupação moura na península. 0 " apreço mouriço da fidelidade, valor e virtude' femininos" era responsável "pelo rígido controle que essas culturas exerciam sobre as mulheres, proibindo-as de sair às ruas, fechando-as no interior das casas, negando-lhes direitos básicos" (QUINTANEIRO, 1996, p. 38).
} 
(...) Percebendo sua ausência [das mulheres] nas salas de visitas e até na sala de refeições, sabendo-as impossibilitadas de caminhar livremente pelas ruas, escoltadas ainda em suas constantes idas à igreja, alguns acreditavam que um dos poucos divertimentos que restava às senhoras e senhoritas brancas, e no qual passavam longas horas, era olhar. (QUINTANEIRO, 1996, p. 36)

Essa prática de ocultar as mulheres teria começado a se alterar no final do século $\mathrm{XIX}$, quando os viajantes passaram a observar "um relacionamento um pouco menos desigual entre os sexos" (QUINTANEIRO, 1996, p. 36). Entretanto, se essa era uma prática cotidiana comum em todos os cantos do Brasil, por que o comentário de Saint-Hilaire teria causado tamanha irritação e descontentamento ao Capitão Versiani a ponto de ser registrada por Gardner?

Muitos pesquisadores têm chamado a atenção para o olhar que os viajantes estrangeiros do século XIX lançaram para o Brasil mediado pelos hábitos, costumes e valores de sua própria cultura e visão de mundo, produzindo estereótipos, preconceitos e generalizações. Esse tipo de olhar, muitas vezes, continua sendo direcionado sem crítica às mulheres em diferentes contextos e momentos históricos. Assim, o que pretendo argumentar aqui é que a representação de mulher resguardada no âmbito do lar, privada do contato com a rua, de filha ou esposa obediente e mãe devotada - características do modelo de mulher burguesa - não pode ser tomada como fixa, invariável e generalizada para todos os contextos históricos, em especial em regiões mais distantes e pouco urbanizadas, como é o caso do sertão norte-mineiro na primeira metade do século XX.

Uma importante historiografia sobre a família e as mulheres assinalou a preocupação e as estratégias das elites brasileiras do final do século XIX e início do XX para instituir e disseminar os modelos idealizados de família conjugal, casamento legítimo, de homens e mulheres, marcados pelas diferenças de gênero, a fim de disciplinar os novos cidadãos, assegurar a maternidade, o controle e a permanente submissão das mulheres. Essas estratégias faziam parte dos projetos de modernização burguesa da sociedade (Cf. COSTA, 1999; D'INCAO, 1997; BESSE, 1999; RAGO, 1997; SOIHET, 1989; MAIA, 2011). Conforme observaram Marina Maluf e Maria Lúcia Mott, muitos intelectuais e políticos se empenharam em manter as distinções entre homens e mulheres e em legitimar a diferenciação entre os papéis sexuais. 
(...) "A mulher que é, em tudo, o contrário do homem", foi o bordão que sintetizou o pensamento de uma época intranqüila e por isso ágil na construção e difusão das representações do comportamento feminino ideal, que limitaram seu horizonte ao "recôndito do lar" e reduziram ao máximo suas atividades e aspirações, até encaixá-las no papel de "rainha do lar", sustentada pelo tripé mãe-esposa-dona de casa. (MALUF; MOTT, 1998, p. 368)

Esse tripé tornou-se a base para a construção do modelo de feminino das primeiras décadas do século XX, mas não foi a regra em todos os contextos, sobretudo na região em estudo. Conforme ressalta Joan Scott (1995, p. 88), "os homens e as mulheres reais não cumprem sempre, nem cumprem literalmente, os termos das prescrições de sua sociedade ou de nossas categorias analíticas".

Os poucos trabalhos da historiografia que colocaram em evidência mulheres do sertão norte-mineiro tenderam a enfatizar o caráter autoritário e violento delas. Mulheres que teriam sido verdadeiras coronelas, conforme definição de Margareth Rago (2004): aquelas que em posição de poder reproduzem o modo de agir masculino patriarcal e privatista. Nessa perspectiva, Cynara Aguiar (2002) nos fez conhecer Preselina Veloso de Aguiar, a Dona Lulu, uma "mandonista” de São João da Ponte - MG; Milene Maurício (1986) e Maria de Fátima Nascimento (2004), a Dona Tiburtina - de quem falarei mais adiante; Alexandre Rodrigues (2013), Ângela Botelho e Carla Anastasia (2012) tornam conhecida Dona Maria da Cruz, grande proprietária de terras e escravos, tendo sob seu comando muitas pessoas, ela teria sido uma das lideranças da primeira revolta anticolonial no Brasil em 1736. Mulher poderosa, culta, altiva e inteligentíssima, que "tanto contribuiu para urbanizar o sertão do S. Francisco", conforme a descrição de Diogo de Vasconcelos (1918, p. 137) e a ficção de Augusta Figueiredo (1994); dirigia sua fazenda com rara habilidade, cuidava dos órfãos, sustentava enfermos e inválidos, provia a educação de todos e casava as moças, conforme Hermes de Paula (2007) ${ }^{5}$.

A essas "donas", amadas e temidas, do sertão, somam-se também as personagens fictícias de Guimarães Rosa, estudadas por Telma Borges (2015), desprovidas de posses -

\footnotetext{
${ }^{5}$ As representações de Dona Maria da Cruz, que transitam entre a imagem de mulher benevolente, culta e civilizadora dos sertões do São Francisco e de uma mulher temida e violenta, são bastante semelhantes às representações construídas da sua contemporânea Dona Joaquina do Pompéu (1752-1824), no sertão do noroeste mineiro, conforme o belíssimo estudo de Gilberto Noronha (2015).
} 
apontando para a percepção de uma sociedade marcada por um conjunto de significados e representações distintas de contextos mais urbanizados, em que esse modelo pode ter se tornado mais predominante em razão do vasto investimento médico, higiênico e político por parte das elites brasileiras.

Cravada no sertão do norte de Minas, Montes Claros, a maior cidade dessa vasta região, ainda era predominantemente rural até a década de 1940 e distante dos grandes centros urbanos. A estação de trem mais próxima (Várzea da Palma, depois Buenópolis) era distante quatro dias de viagem a cavalo, de onde era preciso mais um dia de trem para chegar até a capital Belo Horizonte. A linha férrea da Central do Brasil somente em 1926 chegou à cidade para conectá-la aos grandes centros urbanos e consolidá-la como “empório de comércio regional”, ponto de embarque do gado gordo do sertão e de “mineiros magros para serem baianos em São Paulo", conforme conta Darcy Ribeiro (1997, p. 15).

A primeira motocicleta, o primeiro caminhão e os primeiros automóveis também só chegariam à cidade em 1920, época em que as ruas empoeiradas começaram a ganhar calçamento com pés de moleque, mas por onde continuariam a transitar tropas de mulas

\footnotetext{
${ }^{6}$ Assim como o próprio sertão foi representado. Segundo Janaina Amado, "sertão" é uma categoria construída pelos colonizadores portugueses, durante o processo de colonização, por oposição e ao mesmo tempo complementar ao "litoral", e carregada de sentidos negativos. "Opostas, porque uma expressava o reverso da Outra: litoral (...) referia-se não somente à existência física da faixa de terra junto ao mar, mas também a um espaço conhecido, delimitado, colonizado ou em processo de colonização, habitado por outros povos (índios, negros), mas dominados pelos brancos, um espaço da cristandade, da cultura e da civilização (...)"; sertão, por sua vez, designava os espaços interiores da Colônia, "mas também aqueles espaços desconhecidos, inacessíveis, isolados, perigosos, dominados pela natureza bruta, e habitados por bárbaros, hereges, infiéis, onde não haviam chegado as benesses da religião, da civilização e da cultura", um lugar sem fé, sem lei e sem rei. Para muitos colonos, entretanto, excluídos da sociedade, perseguidos pela coroa ou pela Igreja, o sertão era o lugar "da esperança e da liberdade em relação a uma sociedade que os oprimia" (AMADO, 1995, p. 149-150). Ao longo do século XIX, a categoria sertão vai retomando seu sentido original de interior, mas muitas de suas representações negativas ainda irão persistir. Neste trabalho, uso a expressão "sertão nortemineiro" para me referir à extensa região do norte do Estado de Minas Gerais, conforme a classificação da Secretaria Estadual de Planejamento e Gestão (SEPLAG/MG) e do IBGE. A região compreende 89 municípios dos quais Montes Claros é a cidade polo, sendo coberta predominantemente por cerrado, clima semiárido, com longos períodos de estiagem.
} 
e rangentes carros de bois; muito mais tarde as duas praças da cidade ganhariam jardins e calçadas (SILVEIRA; COLARES, 1995). Apesar da fartura de certos gêneros alimentícios, a cidade tinha uma cultura material muito pobre, "mesmo os ricos não tinham conforto algum, embora em comparação com a plebe vivessem no luxo" (ANJOS, 1994, p. 103-104). Como lembra Cyro dos Anjos em suas memórias: "só mais tarde vim a descobrir a pobreza escondida em muitas casas, onde, se não faltava comida, tão barato era tudo o que vinha das roças, escasseava, entretanto, o dinheiro para o senhorio, para a farmácia, para a loja" (ANJOS, 1994, p. 191). Não obstante a vocação para o comércio, destino dos "meninos de família", os ventos do progresso e da modernização, como se percebe, demoraram mais tempo para soprar na cidade e, junto com eles, os hábitos, costumes e a moralidade burguesa com seus modelos idealizados de família, de homens e de mulheres marcados pelas diferenças de gênero e separados em esferas antagônicas de atuação.

Nesse sentido, minha hipótese é que, apesar do patriarcalismo que governa as relações, nas primeiras décadas do século XX - período de expansão do modelo de mulher e família burguesas no Brasil -, os papéis de gênero não eram tão fixos no sertão norte-mineiro, e as mulheres não estavam submetidas a um modelo de comportamento baseado no que podemos chamar de domesticidade burguesa, em que são valorizados certos aspectos, como fragilidade, doçura, passividade, retidão e submissão. Assim, o objetivo deste artigo é entender as representações de gênero, identificando formas de atuação e insubmissão femininas nas relações sociais e cotidianas. Busca ainda entender os sentidos que tornaram inteligíveis as mulheres nesse contexto geo-histórico ${ }^{7}$.

O gênero é aqui entendido, conforme conceitua Teresa de Lauretis (1994, p. 208), como “"o conjunto de efeitos produzidos em corpos, comportamentos e relações sociais' por meio do desdobramento de "uma complexa tecnologia política"”; a construção do gênero "é tanto produto quanto o processo de sua representação" ( LAURETIS, 1994, p. 216). O gênero é também o modo primário de significar relações de poder (SCOTT, 1995). Nessa perspectiva, compreendo o poder a partir da analítica de Michel Foucault, ou seja, como "multiplicidade de correlações de força" (FOUCAULT, 1995). Não há relação de

\footnotetext{
${ }^{7}$ As representações são aqui empregadas no mesmo sentido que lhes atribui Denise Jodelet (2001), ou seja, são imagens mentais que instituem a realidade, em seus aspectos individual e social.
} 
poder em que as determinações estejam saturadas, a não ser quando o sujeito "pode se deslocar e, no limite, escapar”; "não há relação de poder sem resistência, sem escapatória ou fuga, sem inversão eventual”, sem insubmissão ( FOUCAULT, 1995, p. 243).

A escassez de fontes para a escrita da história das mulheres, apontada por Michele Perrot nos anos de 1980, ainda constitui um grande desafio para os/as historiadores/as interessados/as nos estudos sobre as mulheres e as relações de gênero no passado. Conforme Perrot (2005, p. 14), “olhar de homens sobre homens, os arquivos públicos calam as mulheres". Assim, fazer a história das mulheres no norte de Minas - onde os arquivos de maneira geral são escassos - exige criatividade, um paciente trabalho de garimpo e de escavação em busca de vestígios. Aqui, procuro esses vestígios, escavando as memórias escritas de Cyro dos Anjos e de Darcy Ribeiro ${ }^{8}$ em suas autobiografias, respectivamente: A menina do sobrado, publicada em $1963^{9}$, e Confissões, publicada em $1997^{10}$. Quanto a A menina do sobrado, é dividida em duas partes: "Santana do Rio Verde"

\footnotetext{
${ }^{8}$ Darcy Ribeiro, antropólogo, educador e romancista, filho de Reginaldo Ribeiro dos Santos e de Josefina Augusta da Silveira, nasceu em Montes Claros em 26 de outubro de 1922, onde fez os estudos fundamentais e o secundário. Foi eleito para a Academia Brasileira de Letras em 1992 para a Cadeira $n^{\circ}$ 11, sucedendo a Deolindo Couto. Formou-se em Ciências Sociais pela USP em 1946, passando a se dedicar à etnologia indígena, e, em 1947, fundou o Museu do Índio. Criou a Universidade de Brasília, de onde foi o primeiro reitor. Foi Ministro da Educação e chefe da Casa Civil do Governo João Goulart. Com o golpe militar de 1964, teve seus direitos políticos cassados e se exilou. Viveu em vários países da América Latina, onde lecionou em várias universidades; foi assessor do presidente Salvador Allende, no Chile, e de Velasco Alvarado, no Peru. Em 1976, retornou ao Brasil e foi anistiado em 1980. Voltou a dedicar-se à educação e à política, sendo eleito vice-governador do Estado do Rio de Janeiro (1982). Foi cumulativamente secretário de Estado da Cultura e coordenador do Programa Especial de Educação do Rio, onde também criou a Biblioteca Pública Estadual, a Casa França-Brasil, a Casa Laura Alvim e o Sambódromo. Em 1990, foi eleito senador da República. Recebeu os títulos de Doutor Honoris Causa da Sorbonne, da Universidade de Copenhague, da Universidade do Uruguai, da Universidade da Venezuela e da Universidade de Brasília (1995). Foi autor da atual Lei de Diretrizes e Bases da Educação LDB/1996. Faleceu em Brasília, DF, em 17 de fevereiro de 1997 (ABL). Disponível em: $<$ http://www.academia.org.br/academicos/darcy-ribeiro/biografia $>$.

9 O livro A menina do sobrado veio a público em 1979, reunindo duas partes das memórias de Cyro. A primeira, objeto deste trabalho, foi publicada originalmente em 1963 com o título "Explorações no Tempo" e se refere às lembranças do seu "País da infância”; a segunda, "Mocidade, amores”, até então inédita, relata suas fases de adolescência e juventude na capital mineira, Belo Horizonte. A obra segue o estilo já presente nas anteriores, $O$ amanuense Belmiro e Abdias, com a abordagem de temas que transcendem os fatos biográficos.

${ }^{10}$ Confissões foi o último livro publicado da vasta bibliografia de Darcy. Foi escrito quando lutava contra o câncer que o matou; em suas palavras, "escrevi estas Confissões urgido por duas lanças. Meu medopânico de morrer antes de dizer a que vim. Meu medo ainda maior de que sobreviessem as dores terminais e as drogas heroicas trazendo com elas as bobeiras do barato" (RIBEIRO, 1997, p. 11).
} 
e "Mocidade, amores", que narra sua juventude em Belo Horizonte, detenho-me, neste artigo, somente na primeira parte ${ }^{11}$.

Esses autores nasceram em Montes Claros - Cyro em 1906, Darcy em 1922 -, onde viveram a infância e a adolescência. São as lembranças dessa fase da vida dos autores que se localizam no período que vai da década de 1910 a 1940 - que suscitaram, em particular, a discussão que proponho neste trabalho.

As obras foram escritas muitos anos após os eventos e as imagens narradas. Portanto elas chegam até nós já filtradas e ressignificadas pelo tempo, pelos esquecimentos e pelos processos seletivos da memória, que tende a privilegiar certos acontecimentos. Entretanto, para nós, historiadores/as, são indícios de experiências e vivências do passado; monumentos - conforme acepção de Le Goff (2003) - que evocam o passado, perpetuam a recordação e constroem representações do passado.

Apesar do pacto autobiográfico característico desse gênero literário, conforme Lejeune (2008), não há uma preocupação dos autores com a veracidade dos fatos narrados ou com uma ordem cronológica deles. Como adverte Darcy, “(...) é um mero reconto espontâneo. Recapitulo aqui, como me vem à cabeça, o que me sucedeu pela vida afora, desde o começo (...)" (RIBEIRO, 1997, p. 11). Cyro também segue os fluxos da memória, mas escreve em forma de conto, ficcionalizando nomes de pessoas e de lugares - a começar pelo da cidade, denominada por ele de Santana do Rio Verde. Suas lembranças, conforme esclarece, resultam “da soma de mil experiências em ocasiões distintas, no curso de quase três lustros" (ANJOS, 1994, p. 29)

\footnotetext{
${ }^{11}$ Conforme Afonso Henrique Fávero (1996, p. 10-11), “A menina do sobrado apresenta um mundo que é recuperado pela memória, tendo necessariamente um fundo documental [como a utilização de Efemérides e periódicos] mas que não prescinde de aspectos ficcionais. (...) trata-se, pois, de um livro de memórias inclinado a fazer também história de grupo". As memórias de Cyro são caracterizadas pela "doce ironia, a ternura, a compreensão amável e risonha a revestir todo o passado: componentes basilares da visão lírica com que o mundo é contemplado" (Idem, p. 25). Sobre as representações femininas nos romances de Cyro, consultar Oliveira (2011).

12 Não há, portanto, nos gêneros textuais aqui analisados, a preocupação com um relato coerente e totalizante de si, ou de estabelecer conexões entre os acontecimentos selecionados e narrados para Ihes dar coerência, características dos relatos biográficos destacadas por Bourdieu (2006) em "A ilusão biográfica". O texto de Darcy segue a "lógica da confidência”, como indica o título; e o de Cyro, a de crônicas.
} 
Todavia, para além da distância que separa o tempo das vivências e a respectiva narrativa, é preciso sublinhar ainda que ela constitui um olhar posicionado sobre o feminino, ou seja, são dois homens, brancos, pertencentes a famílias tradicionais da cidade e à elite intelectual do país - ambos imortais da Academia Brasileira de Letras e encarregados de altos cargos políticos e públicos -, os quais, de certa forma, representam o discurso hegemônico. Mesmo assim, penso que suas lembranças e as representações que elas constroem são importantes fontes de indícios da vida das mulheres no passado, as quais nos possibilitam, por um lado, perceber experiências e formas de insubmissão diversas de mulheres em contextos geo-históricos tradicionalmente marginalizados; por outro, nos permitem questionar representações hegemônicas do feminino, bem como abordagens teóricas universalizantes. É nas brechas desses discursos, no space-off de suas representações, conforme Lauretis (1994), que busco identificar e entender a movimentação, os deslocamentos e as insubmissões das mulheres.

\section{Da sala de jantar à rua}

Sentada à grande mesa de Pereiro Branco, na sala de jantar, "caneta entre os dedos e o pulso apoiado à testa", a escrever cartas para a irmã em Outro Preto, numa tarde de domingo. Essa imagem, como uma pintura, é a que Cyro guardou da mãe. “Figura franzina e pequena, a tez levemente rosada, a fronte ampla, os cabelos castanhoclaros, apanhados para trás, e o olhar abstrato sob os óculos de aro dourado" (ANJOS, 1994, p. 37). Trata-se de uma mulher tímida, contida, de ar cerimonioso, quinquagenária já fatigada e envelhecida, quase nunca nomeada pelo filho em suas memórias. Como poucas mulheres nascidas no século XIX - e ao contrário da imensa maioria da população brasileira -, ela tinha um “pé-de-meia cultural”, embora modesto: tocava piano e fora educada nas letras, quando solteira, por isso sabia francês, inglês e latim, para surpresa de Cyro menino.

Tendo dado à luz um filho atrás do outro, num total de 14, ocupava-se de cada um somente até a primeira infância, transferindo-o em seguida aos cuidados de Luísa Velha, 

desde os primórdios da colônia e que, em grande medida, ainda persiste, é o que Sueli Gomes Costa (2002) chamou de maternidade transferida. Ela consiste na transferência de afetos e responsabilidades do cuidado materno para outras mulheres e é parte de uma economia reprodutiva própria do espaço doméstico ${ }^{13}$. Para o menino, a mãe era “(...) apenas uma enseada protetora na hora da zanga paterna" (ANJOS, 1994, p. 35), era uma sombra doce, mas distante e apática. "Da índole, ficou-me a impressão, já comunicada, de mansuetude e placidez. E, pelos reparos que uma vez ou outra fazia às tolices que disséssemos ou aos nossos arroubos e entusiasmos, posso inferir que era sagaz, ponderada e discreta" ( ANJOS, 1994, p. 37).

O casamento, entretanto, não parece ter sido somente resultado de acordo entre famílias, já que o pretendente vinha de família modesta, encontrando por isso resistência por parte de uma tia materna à união do casal. Não obstante a sisudez, a censura e a autoridade inconteste do pai, a aquiescência dessa "dona-de-casa meio filósofa" nas decisões da família indica ter sido considerada e respeitada. Isso se evidencia no episódio da mudança da família para a fazenda Porteirinha, conforme a seguinte narração de Cyro dos Anjos. O pai - Cel. Antônio dos Anjos, homem rígido, autoritário, visto como uma instância suprema, "a suma potestade, ante a qual se paralisavam a palavra e o gesto da prole" - poderia simplesmente impor sua vontade e decisão que, segundo o narrador, seriam acatadas pelos demais membros da família sem contestação; entretanto, o marido utilizou várias estratégias e artimanhas - como a promessa de um amplo pomar - para convencer a esposa a aderir de bom grado ao seu projeto. Conforme conclui Cyro, “(...) equivoquei-me por muito tempo, ao imaginar que entre os dois apenas houvesse acomodação de temperamentos, tendo um nascido para mandar, a outra, para obedecer; gostando ele de falar, e ela, de calar..." ( ANJOS, 1994, p. 40).

As lembranças de Cyro indicam que não havia uma rigorosa interdição das mulheres em certos espaços públicos. Se Ihes eram interditados os espaços políticos e

\footnotetext{
${ }^{13}$ Esse tema será retomado e desenvolvido mais adiante.
} 
decisórios - como de resto à imensa maioria da população pobre e analfabeta -, elas, ao contrário, estavam presentes nos espaços de sociabilidade e de cultura: nas serenatas e serestas, nos bailes, nas festas tradicionais, no carnaval de rua, na igreja, no comando de banda de música e corais, no cinema e no teatro - como plateia e intérpretes - e nas conversas com os rapazes. Elas estavam na escola mista como alunas ou como professoras, a exemplo de Mestra Eponina, Professora Deolinda, a "solteirona"14, Floripes, entusiasta declamadora, e Mestra Fininha, mãe de Darcy Ribeiro, de quem falarei mais adiante.

É nesses espaços que Cyro rememora seus amores da adolescência, como Maria da Glória, que viria a recusar o casamento com um juiz, melhor partido da cidade, em prol de um caixeiro-viajante, para a indignação das "damas santanenses"; e Priscila, sua primeira "namorada". De família humilde, composta por irmãos menores e um pai viúvo, descrito como jogador e folgazão, a donzela Priscila não vivia resguardada em casa e sob o olhar vigilante e protetor do pai, à espera de um bom partido para o casamento; ela, ao contrário, fora entregue à "gestão de si mesma" (ANJOS, 1994, p. 161). A casa também fora deixada sob o governo dessa jovem donzela, que estava frequentemente sem dinheiro, "mesmo para as despesas de rotina".

Pelo espaço da rua também circulavam, conforme registro de Cyro, damas de alta prosápia, em relações extraconjugais, as mulheres-damas da rua do Marimbondo - muitas delas sempre à espera de algum amante que lhe montasse casa -, vendedoras, artesãs, costureiras, donas de pensão e muitas empregadas domésticas.

\footnotetext{
${ }^{14}$ A construção do estereótipo da solteirona acompanha a constituição e expansão do modo de vida burguês. No Brasil, esse estereótipo foi construído e amplamente utilizado a partir, sobretudo, do final do século XIX até meados do século XX, como modo de desqualificar as mulheres que não aderiam à conjugalidade burguesa, funcionando como uma forma de "terror moral" que coagia as mulheres ao casamento e à maternidade; ao mesmo tempo, a representação da solteirona como uma mulher invejosa, rancorosa, desvio da natureza, digna de misericórdia, confirmava a ideia de esposa/mãe feliz e realizada. Uma das estratégias para construção do estereótipo foi a desqualificação por meio da comicidade, assim foram criados pela literatura vários personagens de tipos risíveis e jocosos (Cf. MAIA, 2011). O próprio Cyro dos Anjos usa essa estratégia de escrita ao se referir à "moça Floripes, professora já trintona” (ANJOS, 1994, p. 18); em O Amanuense Belmiro, as “manas velhas” Emília e Francisquinha também são solteironas, mas nessa obra são outros os sentidos usados na construção das personagens, como o mau humor, a esquisitice e a loucura (Cf. ANJOS, 2001; MAIA, 2011, p. 75-83).
} 
A imagem feminina que percorre as memórias de Cyro em Santana/Montes Claros, seja no espaço familiar ou no público, é de "Tia Perpétua" - nome fictício de D. Carlota Fróis dos Anjos, sua tia paterna. Além de lhe ser dedicado um capítulo, ela é frequentemente lembrada na narrativa, em seus adágios, ditados ou opiniões a respeito da família, da política local, de pessoas e acontecimentos. Isso sinaliza para a importância da influência e da efetiva interferência da tia na vida da família e da cidade. Ela enviuvara ainda jovem e, na condição de viúva, pôde governar sua própria vida, enquanto tentava também governar a dos outros. Da janela do seu sobrado no Largo de Cima, inteirava-se dos acontecimentos e dos mexericos por meio do vai e vem no Mercado e seus arredores, por onde passava toda a cidade. A descrição que Cyro faz da tia vai de reverente a cômica, tornando-a quase numa megera, numa imagem, entretanto, que muito se distancia daquela de mulher frágil e dócil:

(...) o rude convívio, a palavra ríspida, o cenho carregado, a inóspita verruga, os amuos e silêncios, pesados e agressivos (...). A essa época, devia ter ultrapassado os oitenta anos. Era de estatura média, gordanchuda, possuía bigodes e dois ou três compridos pêlos nasciamIhe duma verruga do queixo... ( ANJOS, 1994, p. 49-50)

O narrador atribui o caráter duro, indomável, a rispidez e o mau humor de Dona Perpétua à herança dos parentes provenientes das barrancas do rio Verde; pessoas duras, galegas de procedência, que se "embrenharam no sertão mineiro, ao tempo das bandeiras baianas" (Idem, Ibidem). Viúva rica, era dela o segundo automóvel a circular na cidade em 1920, uma "barata" Ford, para a surpresa da família. "Foi considerado a maior revolução o haver Tia Perpetua comprado um carro para seu uso. Era notória a sua prevenção contra as máquinas, e mais de um adágio inventara para fulminá-las (...)" ( ANJOS, 1994, p. 183). Dona Perpétua, que sofria de "cavos" na planta dos pés, quase não podia sair de casa; comprou a "baratinha" para passear todas as tardes e acompanhar o progresso da cidade, sempre em companhia da neta de uma das filhas dos vizinhos e, às vezes, de Cyro, já rapazinho. 


\section{Mulheres brabas, bravas mulheres...}

Como Tia Perpétua, imagens de mulheres "indomáveis" e insubmissas - bravas e brabas - também circulam nas memórias autobiográficas de Darcy Ribeiro. Dentre elas, sua bisavó paterna, Dona Maria, descrita como uma mulher bela, forte e temida, que “(...) reinou décadas, todo-poderosa sobre a família e arredores", governando bens e vidas. Uma das façanhas de Dona Maria, narradas por Darcy, foi a de ter casado seu amante de trinta e poucos anos com a filha de doze, somente para mantê-lo junto de $\mathrm{si}^{15}$. O amante, Simeão Ribeiro dos Santos, viria a se tornar um dos coronéis mais importantes da região, presidente da Câmara de Montes Claros, em 1898, e pai das principais personalidades da vida política, econômica e intelectual da cidade na primeira metade do século XX (RIBEIRO, 1997, p. 29). Essa matrona-coronela nascida no século XIX não parece ter sido uma mulher submissa e obediente; ao contrário, ela impunha a obediência e a submissão de muitos pela autoridade e violência que exercia, como atesta Darcy:

(...) Certa vez, a menina escrava que servia seu almoço começou a chorar convulsivamente e confessou que tinha envenenado a comida. Ela só disse: "sua mão há de secar!".

Mandou dar uma surra na pretinha - e não é que a mão dela secou mesmo? ( RIBEIRO, 1997, p. 29)

Outra mulher representada nas memórias de Darcy como uma das “mais bravas do Brasil" é a controversa Dona Tiburtina. Mulher inteligente, astuta e de rara beleza, chegou a Montes Claros em 1902. Enviuvando-se em seguida, foi obrigada a sustentar sozinha a família com seu ofício de costureira. Conquistou um dos melhores partidos da cidade, o jovem médico João Alves, com quem se casou.

Conforme Darcy (1997, p. 42), Tiburtina "tornou-se a mais querida e a mais odiada em razão dos ódios partidários e dos gostos pessoais". Ela ganhou a simpatia e a devoção da cidade ao auxiliar o marido no cuidado com os doentes, sobretudo ao enfrentar junto com ele a epidemia da gripe espanhola em 1918. Por outro lado, foi acusada pelos adversários políticos do marido - líder do Aliança Liberal - de ter sido a mandante de um

\footnotetext{
${ }^{15}$ Esse episódio também é narrado por Nazinha Coutinho, prima de Darcy, em seu romance autobiográfico Maria Clara (Cf. COUTINHO, 1978).
} 
atentado à comitiva do então vice-presidente da República, Fernando de Melo Viana, em visita a Montes Claros, acompanhado de deputados e altos funcionários, para, sob pretexto de um Congresso de Algodão, realizar campanha para Júlio Prestes à presidência da República pela Concentração Conservadora. O episódio, ocorrido em 6 de fevereiro de 1930, e que resultou em seis mortes e muitas pessoas feridas, tem sido apontado pela historiografia regional - e, também, por Darcy - como o primeiro, dentre outros acontecimentos, responsável pelo desencadeamento da chamada "Revolução de 1930". Sobre o episódio, foram construídas várias versões que vão de uma emboscada ardilosamente arquiteta por D. Tiburtina - versão construída pelos jornais ligados à Concentração Conservadora - a apenas um incidente que deu início a um descomunal tiroteio, com seis mortos, dentre eles uma mulher e muitos feridos dos dois lados ${ }^{16}$. Após esse episódio, Dona Tiburtina passou a ser representada na imprensa nacional como facínora, “fera humana”, “guerrilheira sertaneja” (NASCIMENTO; REIS, 2015, p. 222).

Milene Maurício, em seu livro Emboscada de Bugres, e Maria de Fátima Nascimento (2004), em biografia histórica de Dona Tiburtina, argumentam, entretanto, que essa imagem de mulher má e temida, chefe de jagunços, foi uma criação dos adversários políticos do marido, como forma inclusive de desqualificá-lo. Darcy, por sua vez - sem fazer eco aos que acusaram Tiburtina de mandante da tocaia - rememora as lembranças dela, de quando era garoto, e testemunha a posição de poder que ela tinha sobre vidas e pessoas:

(...) Lembro-me dela pouco antes de morrer. Havia deixado de pintar os cabelos e mostrava uma faixa branca que ia da testa até o meio da cabeça $[\ldots]$

Tiburtina era amiga de minha avó e estava em nossa casa, em visita, quando lá entrou, espavorida, a mulher do barbeiro mais conhecido e falante da cidade. A pobre ajoelhou-se aos pés de Tiburtina, chamando-a "minha madrinha" e implorando que não matasse o seu marido, que os jagunços haviam tirado de casa naquele momento. Recordo bem as mãos de Tiburtina alçadas acima da cabeça da mulher, sem tocá-la, mandandoa para casa. (RIBEIRO, 1997, p. 42-43)

\footnotetext{
${ }^{16}$ Cyro, que se posicionava a favor da Aliança Liberal e, à época, escrevia editoriais para o Diário de Minas sobre os acontecimentos políticos daquele ano, em entrevista ao Diário de Montes Claros em maio de 1983, também considera o acontecimento um incidente, resultado do clima de rivalidades, provocações e do pé de guerra que se instalou na cidade com as duas facções se armando e convocando a jagunçada (In: MAURíCIO, 1986, p. 148-151).
} 
A representação de "mulher brava" - frequente na literatura memorialista, na historiografia regional e na tradição oral -, para se referir a mulheres norte-mineiras, acessa a dupla significação que encerra o adjetivo. Algumas vezes, "brava" aparece como sinônimo de indomável, valente, selvagem, incivilizada, como o próprio sertão foi percebido: lugar sem lei e sem rei; ou seja, sem regras e sem governo (AMADO, 1995). O termo assume, nesse caso, um sentido negativo de braba, brabeza, barbárie. São esses sentidos que constroem as representações das donas do sertão, mulheres, como a Dona Perpétua, tia de Cyro, a Dona Maria, bisavó de Darcy, ou Dona Tiburtina - esta última já cristalizada no imaginário regional -, ou, ainda, Dona Lulu e Dona Maria da Cruz, já referidas no início deste texto.

Em outros momentos, "brava” assume conotação positiva, aparecendo como sinônimo de corajosa, intrépida, heroica, aguerrida ${ }^{17}$. Esse é o caso, por exemplo, de Mestra Fininha, mãe de Darcy. "Mamãe foi uma brava mulher, com energia e coragem para completar o seu curso normal depois de viúva, enfrentar o trabalho de criar, sem ajuda, seus dois filhos. Acabou por criar também seus irmãos mais novos" (RIBEIRO, 1997, p. 26-27). Viúva aos 23 anos e com dois filhos pequenos, após a morte do marido, e lesada na herança pelos parentes dele, Fininha se viu obrigada a deixar a casa espaçosa e confortável onde vivia com a família e retornar à casa paterna. "[D]esempregada, se desdobrava fazendo doces e bolos para todo tipo de festas" (RIBEIRO, 1997, p. 31). Na década de 1920, época em que não havia muitas oportunidades de trabalho remunerado para as mulheres, sobretudo numa cidade pouco urbanizada como Montes Claros, como já se falou, ela conseguiu construir uma rara carreira profissional no magistério, que lhe proporcionou não só sustentar a família como também o reconhecimento do município pelos seus méritos de professora ${ }^{18}$.

Felismina Pimenta Ribeiro, a tia Neném, é outra mulher que emerge na narrativa de Darcy com esse segundo sentido de brava. Quando adolescente, desacatando o pai e

\footnotetext{
${ }^{17}$ Gilberto Noronha também observou essa dualidade do termo brava na construção de representações sobre Dona Joaquina do Pompéu: "Mulher brava, 'enérgica, forte e varonil', mas que não é braba não. Quer dizer, sua bravura é vista como um valor positivo, enaltecedor, ao contrário da brabeza, que traz um significado intrínseco de maldade - valor negativo" (NORONHA, 2015, p. 192).

${ }^{18}$ Uma das principais avenidas da cidade leva seu nome.
} 
realizar o casamento, até ser capturada pelos capangas do pai. Foi internada num colégio de freiras em Belo Horizonte, mas isso não foi suficiente para domesticá-la. Posteriormente, ela se graduou em Farmácia, tornando-se uma das primeiras mineiras a cursar a universidade. Conforme Darcy: “Neném era politiqueira, brava e temida. Todos a respeitavam demais. Inclusive o marido" (Idem, p. 33), Plínio Ribeiro - tio paterno de Darcy -, um dos principais intelectuais da cidade, médico, empresário rico e político.

Das lembranças de Darcy e Cyro surgem ainda imagens de mulheres bravas/brabas que não tiveram a mesma sorte que aquelas de ciclos familiares bem remediados. Darcy fala de prostitutas - descritas pelo olhar lascivo do narrador-consumidor de sexo -, como Almerinda: “(...) puta alta, cabelos pretos, bunduda, bonitona, a mais cotada da cidade” (Idem, p. 64). Mesmo na sua condição precária - de prostituta, pobre e analfabeta -, Almerinda afirmava orgulhosa sua liberdade e independência, ao gritar "para quem quisesse ouvir" que não ganhara nada de homem algum e que conquistara um dente de ouro e a casinha da mãe com seu trabalho de prostituta na zona de meretrício.

Cyro, por sua vez, fala de várias empregadas domésticas - da família ou frequentadoras da sua casa -, dentre as quais, aquelas que ele classifica como sendo as de "gênio brabo": Maria Veado, temida pela meninada, pois "sabia-se que dera uma facada nas partes posteriores do seu pai, por ter este ousado aliviar-se de gases em sua presença” (ANJOS, 1994, p. 32); Felisbina, pouco respeitada por Luísa Velha, porque tinha “um parafuso a menos"; e Joaquina Gomes, a "carrancuda serviçal” do vigário, que recolhia as esmolas para a igreja na missa dos domingos.

Nesse rol de mulheres "brabas" está ainda a "aloprada" Ritinha do Amaro. Ela, que tinha como principal alegria mandar "dizer missa com foguetório e banda de música" em todo 13 de maio pela alma da Princesa Isabel, gastava todo o dinheiro juntado ao longo do ano com a venda de doces, no banquete à sombra das jaqueiras de seu quintal, oferecido aos "figurões da terra" como parte das comemorações (ANJOS, 1994, p. 32). Hermes de Paula, o principal memorialista de Montes Claros, também dá notícia dos 
quitandeira, e era requisitada com frequência para comandar a cozinha das grandes festas, sobretudo das famílias mais abastadas. Conforme Hermes de Paula, ela era também a carpideira-mor dos defuntos ricos, “morria alguém de família importante, lá estava Ritinha soluçando" (PAULA, 2007, p. 20). Izabelona, que também aparece nas memórias de Cyro, era proprietária de um restaurante “de vida noturna intensa e, até certo ponto, suspeita" (ANJOS, 1994, p. 115), onde servia saborosas e afamadas ceias depois da meia-noite. Conforme Hermes de Paula,

(...) a maior satisfação de Izabelona era ser "xará" da Princesa Libertadora. E quando, no final do almoço, os oradores se sucediam com a força do vinho, brindando Isabel - a Redentora, a anfitriã, comovida, recebia todos os elogios, convencida de que estavam sendo dirigidos a ela - Izabelona. (PAULA, 2007, p. 20)

Essas mulheres, à exceção de Izabelona, descritas por Cyro com certa ironia, faziam parte do "círculo das fâmulas", que se reunia em torno de Luísa Velha na cozinha da família dos Anjos.

\section{A diferença classe/raça entre mulheres}

Na família extensa de Cyro dos Anjos, o mundo da cozinha era comandado por Luísa, preta velha de peitos murchos, voz fatigada, idade desconhecida, "carapinha encoberta por um lenço-de-alcobaça"; trazia consigo figas ao pescoço e um cordel de bentinhos e verônicas. Pela cozinha de Luísa, circulavam muitas mulheres que compunham a classe das serviçais da cidade, trazendo novidades da terra e levando recados da velha empregada, afastada do mundo externo pelo reumatismo. Além das mulheres do "gênio brabo" já referidas, Cyro busca outras em suas memórias mais antigas, trazendo para a narrativa aquelas que classifica como sendo do grupo das reverentes e doces: a "lamurienta" Siá Eva, apelidada de Tudo-Me-Dói, pois, "miudinha, sempre queixosa, poço de doenças"; Rosaura, também conhecida como Rosaura das 

“ingrata Siá Máxima”.

Do grupo das domésticas, a que gozava de maior autoridade ao lado de Luísa Velha era a sábia Maria Parteira, ex-escrava do avô de Cyro. Herdara deste uma casinha no Beco do Urubu, mas continuava a frequentar todas as tardes a casa da família dos Anjos e auxiliava Luísa, quando havia muitos hóspedes. "Em tempos imemoriais, fora uma cozinheira preclara. Recordando antigos jantares à mesa do meu Avô, Loiola a equiparava a um Goethe, um Shakespeare ou um Dante, no mundo da arte culinária, que, a seu ver, trazia aos homens mais felicidade que o da poesia" (ANJOS, 1994, p. 31). Maria Parteira legara a Luísa a colher de pau, o emblema de poder na cozinha e, junto com ela, as atividades relativas ao cuidado das crianças pequenas da família.

Assim, Luísa Velha, no tempo de Cyro menino, ditava as regras da cozinha, mas também do cotidiano e de entendimento do mundo dos meninos daquela família, por meio de suas estórias - de aplicação imediata -, costumes e crenças populares. Desde pequenas, as crianças ficavam sob os cuidados dessa ama-preta, fortemente presente nas memórias de Cyro. Como conta o narrador, na primeira quadra da vida, ele e o "mano" Benjamim foram criados na "barra da saia da preta velha", de "(...) cujo intermédio tudo nos vinha: a comida, a roupa, o remédio, o sono, a defesa ante o perigo, o amuleto contra mau-olhado, e até o alimento que o espírito reclamava, sob a forma de contos e causos", o embalo do berço, as cantigas para ninar e o colo para os acalantar. Da mãe, não se lembra de ter recebido afagos, "além do olhar manso que acaso pousava sobre mim" ( ANJOS, 1994, p. 35).

Conforme sublinhei antes, a maternidade transferida é uma prática que remonta à formação da sociedade brasileira (COSTA, 2002) e corresponde à delegação das atividades do cuidado maternal, especialmente nas famílias mais abastadas, às escravas. A figura da ama de leite, a "ama preta", cristalizada no imaginário social e registrada pela historiografia - como nos trabalhos precursores de Gilberto Freyre, Emília Viotti da Costa e Caio Prado Jr., dentre outros -, retrata com precisão essa prática. Elizabeth Carneiro 
(2001), ao perscrutar essa historiografia em busca de tais figuras, observou, entretanto, que a imagem da "ama negra" é invocada como elemento narrativo que, de certa forma, suaviza a escravidão no Brasil. Elas aparecem como,

(...) Mulheres destituídas de expressão própria ou política, desprovidas de seus corpos e destinos (...) Com cheiro de quitutes, a imagem negra de mulher mãe figura no palco minado pelos conflitos de classe e derrama afetividade no imaginário, tornando mais leve e mais suave o peso e o jugo da escravidão na memória social. (CARNEIRO, 2001, p. 4445)

Essa imagem da mãe preta terna, "amaciadora dos embates da vida" (Idem, Ibidem), que participava da intimidade da família e gozava de posição "respeitada" e “invejada" por outros cativos, talvez ainda mais presente na literatura, como nas memórias de Cyro, é também, para Rita Segato (2007, p. 158), uma forma de minimizar a violência da escravidão. Ela chama atenção para a precarização do trabalho doméstico pós-abolição que, em certos casos, pouco alterou a situação das trabalhadoras, especialmente das amas, que continuaram a ser consideradas parte da casa.

Assim, embora gozasse de respeito e autoridade sobre os meninos, bem como sobre os serviçais de dentro e os de fora da casa, Luísa parece ter sido mais uma escrava que a Lei Áurea não libertou. A “doce” lembrança de Luísa acessa a imagem de muitas mulheres pobres do período, que dedicaram suas vidas a cuidar da cozinha e dos filhos de outras mulheres - mais abastadas -, não tendo elas seus próprios filhos ou sua casa ${ }^{19}$. A maternidade transferida, que de diferentes maneiras se reatualiza na sociedade pósabolição, possibilita a certas mulheres "atribuírem-se mútuas responsabilidades" (COSTA, 2002, p. 303), encobrindo as desigualdades, em cascata, entre mulheres. Assim, à medida

\footnotetext{
${ }^{19}$ Outro exemplo dessa situação que viveram as ex-escravas é encontrado no livro de Hermes de Paula - um misto de memórias, tradição oral e pesquisa documental. Segundo ele, o maior liberal e abolicionista de Montes Claros no período, Camilo Prates, quando teve seu filho, mandou pedir a seu pai que lhe enviasse uma ama de leite, mas que fosse livre, pois o filho não se "alimentaria de leite escravo". Conforme o memorialista, pouco depois "chegava na cidade uma preta, que por sinal se chamava Branca, com a carta no baú. 'Mamãe Branca', como ficou sendo chamada, apesar de livre, viveu até a morte em casa de Camilo Prates, cercada de amor e carinho" (PAULA, 2007, p. 19, grifos meus). Camilo Prates fundou, em 1887, a Sociedade Beneficente Emancipadora e, para marcar o início das atividades da Sociedade, libertou a escrava de nome Carolina.
} 
que ocorria certa valorização monetária do trabalho doméstico feminino, as mulheres adultas iam sendo substituídas por meninas, que prescindiam de serem pagas.

Nessas condições de precariedade é que, mais tarde, iriam figurar, nas lembranças de Darcy, as criadas domésticas, consideradas os motores das casas abastadas da cidade. Conforme ele explica, eram meninas pobres trazidas das fazendas e que, sem receberem salário, encarregavam-se de todo o serviço da casa. Recebiam como pagamento “(...) restos de roupas e sapatos. O pior é que não tinham nenhum contato externo, o que as impedia de namorar e se casar. Envelheciam e morriam no serviço, aparentemente muito queridas como pessoas da família, mas de fato escravas vitalícias" (RIBEIRO, 1997, p. 17). Dóia e Maria - criadas da família de Darcy - são exemplos dessas incontáveis mulheres, de certa maneira, exploradas por outras mulheres, seguindo e reproduzindo a lógica do sistema patriarcal capitalista, com suas adaptações e/ou subversões no sertão ${ }^{20}$.

\section{Considerações Finais}

Joan Scott, em seu clássico artigo "Gênero: uma categoria útil de análise histórica", argumenta que o gênero, enquanto elemento constitutivo de relações sociais fundadas sob as diferenças, implica a existência de quatro elementos. O primeiro são os símbolos que temos culturalmente à nossa disposição e que evocam representações simbólicas das mulheres, quase sempre contraditórias, como Eva e Maria, símbolos de pecado e santidade, mas também mitos da poluição e purificação, corrupção e inocência (SCOTT, 1995, p. 86). Nas memórias autobiográficas aqui analisadas, os sentidos utilizados para construir representações de mulheres no sertão norte-mineiro parecem ser outros, embora também, de certa forma, contraditórios. As mulheres transitam entre imagens de heroísmo e valentia, insubmissão e até selvageria - frequentemente

\footnotetext{
20 Essa prática, como salienta Costa (2002), tem longa duração. Rosana de Jesus dos Santos, em estudo sobre as empregadas domésticas na cidade de Montes Claros em período mais recente, verifica a permanência desse tipo de relação descrita por Darcy Ribeiro e, através da análise de processos-crime, verifica a violência física na relação entre patroas e empregadas. Para essa autora, as "representações da mulher doméstica foram construídas ao longo da história, com atributos de um sujeito feminino, inferiorizado, cujo corpo e trabalho poderiam ser apropriados pelas patroas (SANTOS, 2012, p. 191).
} 
evocadas no adjetivo brava -, mas não no sentido de domesticação, passividade e fragilidade.

Percebe-se, contudo, que, apesar de as mulheres mais jovens desfrutarem de certa liberdade de movimento em espaços públicos, como frequentar os saraus, as serenatas, os bailes, as festas tradicionais, a escola mista etc., não se pode afirmar que elas estavam em posição de igualdade com os homens ou que compartilhavam a mesma condição de qualificação, oportunidades ou posição social. Isso pode ser percebido na narrativa de Cyro, mais rica em detalhes. Seguindo uma rigorosa hierarquia familiar, os dois irmãos mais velhos do autor foram encaminhados para se formarem "doutores" na capital; os outros filhos homens foram introduzidos um a um, conforme a idade, numa atividade produtiva - a loja, a farmácia, o correio, a fazenda -; também um a um, conforme a hierarquia de idade, eles eram levados pelo pai para conhecer a capital ou acompanhá-lo a trabalho no Rio de Janeiro. A mesma situação, entretanto, não se observa com as irmãs, já que o autor se refere somente aos irmãos, o que deixa a impressão de tratar-se de um costume que era prerrogativa restrita aos homens da família.

O modelo de família conjugal burguesa ${ }^{21}$, por sua vez, composta pelo casal com um número reduzido de filhos e regida por uma rígida divisão sexual de papéis e funções, sendo homens e mulheres posicionados em esferas antagônicas de atuação, não parece ter sido predominante em Montes Claros no período em análise. Cyro e Darcy narram formas variadas de organização da vida familiar, a exemplo de suas próprias famílias. A de Cyro está próxima do modelo de família patriarcal extensa, formada por muitos filhos e empregados, além dos "parentes que se criavam na casa", regida por uma rígida hierarquia, inflexível disciplina e autoridade incontestável do pai - denominado pelo autor de "a entidade poderosa", embora, conforme assinalei, a voz da mãe fosse ouvida e considerada nas decisões da família. A família de Darcy transitou de uma família mais extensa para uma singular, após a morte do pai, sendo formada pela mãe viúva e os

\footnotetext{
${ }^{21}$ Sobre o conceito de família conjugal burguesa, cf. Jurandir Costa (1999). O longo debate sobre a historiografia da família no Brasil, em especial a crítica ao argumento de que a família patriarcal extensa, predominante no período colonial, foi substituída pelo modelo conjugal burguês no final do século XIX, pode ser acompanhado nos trabalhos de Mariza Corrêa (1994) e Cândice Souza e Tarcísio Botelho (2001).
} 
dois filhos. Nessas e em outras famílias, as mulheres não parecem estar submissas a formas de comportamentos baseados na domesticidade, recato, comedimento, docilidade, restritas ao âmbito doméstico e às atividades ligadas à maternidade e à administração da casa - características das mulheres nas famílias burguesas.

Se essas memórias revelam diferenças de gênero, elas deixam entrever também a diferença e a desigualdade entre determinadas mulheres, diferenças estas percebidas na exploração das mais pobres, como as empregadas/criadas domésticas, pelas que estão em melhor posição social e econômica. Ou, ainda, a crueldade destas com aquelas, como no caso citado por Darcy, da avó Dona Maria, que mandou surrar a menina escrava da casa, por esta ter supostamente colocado veneno na comida.

As representações de gênero são históricas e podem se diferenciar no interior de uma mesma sociedade, por isso estudos com enfoques regionais, como este, podem oferecer importantes contribuições para a história das mulheres e para entender as especificidades das relações sociais, das práticas culturais e representações que constituem os significados de mulheres no espaço e no tempo.

\section{Referências}

AGUIAR, Cynara Silde Mesquita Veloso. Coronelismo em São João da Ponte (1946-1996). Montes Claros: Unimontes, 2002.

AMADO, Janaina. Região, sertão, nação. Estudos Históricos, Rio de Janeiro, v.8, n.15, 1995, p.145-151.

ANJOS, Cyro. A menina do sobrado. Rio de Janeiro; Belo Horizonte: Garnier, 1994.

ANJOS, Cyro. 0 amanuense Belmiro. 16 ed. Belo Horizonte: Garnier, 2001.

BESSE, Susan K. Modernizando a desigualdade: reestruturação da ideologia de gênero no Brasil (1914-1940). Trad. Lólio Lourenço de Oliveira. São Paulo: Endusp, 1999. 
BORGES, Telma. Mulheres que desenredam a tradição no sertão de Guimarães Rosa: uma leitura de "A vela ao diabo" e 'Desenredo". In: MAIA, Cláudia; PUGA, Vera (Orgs.) História das mulheres e do gênero em Minas Gerais. Florianópolis: Ed. Mulheres, 2015, p.243-253.

BOTELHO, Ângela; ANASTASIA, Carla. D. Maria da Cruz e a sedição de 1736. Belo Horizonte: Autêntica, 2012.

BOURDIEU, Pierre. A ilusão biográfica. In: FERREIRA, Marieta de Moraes; AMADO, Janaína (Orgs.). Usos \& abusos da história oral. 8. ed. Rio de Janeiro: FGV, 2006, p.183192.

CARNEIRO, Maria Elizabeth Ribeiro. Procuram-se Amas-de-leite na historiografia da escravidão: da "suavidade do leito-preto" ao "fardo" dos homens brancos. Em tempo de História. Brasília, UnB, v.5, n.5, p.29-64, 2001.

CORRÊA, Mariza Repensando a família patriarcal. In: ALMEIDA, Maria Suely Kofes (Org). Colcha de retalhos: estudos sobre a família no Brasil Campinas: UNICAMP, 1994, p.15-34.

COSTA, Jurandir Freire. Ordem médica e norma familiar. 4 ed. Rio de Janeiro: Graal, 1999.

COSTA, Suely Gomes. Proteção social, maternidade transferida e lutas pela saúde reprodutiva. Estudos Feministas, Florianópolis, n.2, 2002, p. 301-323.

COUTINHO, Nazinha. Maria Clara. Rio de Janeiro: Dois Irmãos, 1978.

D'INCAO, Maria Ângela. Mulher e família burguesa. In: PRIORE, Mary Del. História das mulheres no Brasil. São Paulo: Contexto, 1997, p.223-240.

FÁVERO, Afonso Henrique. As memórias de Cyro dos Anjos. Revista da ANPOLL, n.2, p.9$25,1996$.

FIGUEIREDO, Augusta. Maria da Cruz e o Velho Chico. 4 ed. [S.I. : S.n.],1994.

FOUCAULT, Michel. O sujeito e o poder. In: DREYFUS, Hubert; RABINOW, Paul. Michel Foucault: uma trajetória filosófica para além do estruturalismo e da hermenêutica. 2. ed. Rio de Janeiro: Forense Universitária, 1995, p.231-250.

GARDNER, George. Viagem ao interior do Brasil. Belo Horizonte: Itatiaia, 1975.

JODELET, Denise. Representações sociais: um domínio em expansão. In: JODELET, Denise (Org.). As representações sociais. Rio de Janeiro: Eduerj, 2001, p. 17-44. 
LAURETIS, Teresa de. A Tecnologia do gênero. Tad. de Suzana Funck. In: BUARQUE DE HOLLANDA, Heloisa. Tendências e impasses: o feminismo como crítica da cultura. Rio de Janeiro: Rocco, 1994, p. 206-242.

LE GOFF, Jacques. Documento/monumento. In: LE GOFF, Jacques. História e memória. 5 ed. Trad. Bernardo Leitão et al.. Campinas: Unicamp, 2003, p.525-541.

LEJEUNE, Philippe. Autobiografia e ficção. In: LEJEUNE, Philippe. 0 pacto autobiográfico: de Rousseau à Internet. Belo Horizonte: UFMG, 2008, p.103-112.

MAIA, Cláudia Jesus. A invenção da solteirona: conjugalidade moderna e terror moral Minas Gerais (1890-1948). Florianópolis: Ed. Mulheres, 2011.

MALUF, Marina; MOTT, Maria Lúcia. Recônditos do mundo feminino. In: NOVAIS, Fernando (Org.) História da vida privada no Brasil. v.3. São Paulo: Companhia das Letras, 1998, p.365-421.

MAURíCIO, Milene Coutinho. Emboscada de bugres: Tiburtina e a revolução de 1930. Belo Horizonte: Secretaria de Estado da Cultura: Imprensa Oficial, 1986.

NASCIMENTO, Maria de Fátima Gomes Lima. Tiburtina de Andrade Alves: entre as relações de poder e as representações sociais de uma mulher (Montes Claros, primeira metade do século XX). 2004, 177f. Dissertação (Mestrado em História) - Universidade Severino Sombra, Vassoura (RJ), 2004.

NASCIMENTO, Maria de Fátima Gomes Lima; REIS, Filomena Luciene Cordeiro. Dona Tiburtina de Andrade Alves e a "tocaia dos bugres" no sertão nortemineiro". In: MAIA, Cláudia; PUGA, Vera (Orgs.) História das mulheres e do gênero em Minas Gerais. Florianópolis: Ed. Mulheres, 2015, 213-242.

NORONHA, Gilberto Cézar de. Joaquina do Pompéu: Sinhá Braba ou Dama do Sertão? In: MAIA, Cláudia; PUGA, Vera (Orgs.). História das mulheres e do gênero em Minas Gerais. Florianópolis: Ed. Mulheres, 2015, p.183-212.

OLIVEIRA, Geuvana Vieira de. A representação feminina nos romances de Cyro dos Anjos. Belo Horizonte, MG, 2011. 105 f. Dissertação (Mestrado) - Universidade Federal de Minas Gerais, Belo Horizonte, 2011.

PAULA, Hermes Augusto. de. Montes Claros sua história sua gente seus costumes - Parte I. Montes Claros: Unimontes, 2007. (Coleção sesquicentenária).

PERROT, Michelle. As mulheres ou os silêncios da história. Bauru: EDUSC, 2005. 
QUINTANEIRO, Tânia. Retratos de mulher: o cotidiano feminino no Brasil sob o olhar de viageiros do século XIX. Petrópolis: Vozes, 1996.

RAGO, Margareth. Do cabaré ao lar: a utopia da cidade disciplinar, Brasil (1890-1930). Rio de Janeiro: Paz e Terra, 1997.

RAGO, Margareth. Feminismo e subjetividade em tempos pós-modernos. In: COSTA, Cláudia L.; SCHIMIDT, Simone P. (Orgs.) Poéticas e políticas feministas. Florianópolis: Ed. Mulheres, 2004, p.31-42.

RODRIGUES, Alexandre. A rebelde do sertão: Maria da Cruz e o motim de 1736.Varia História, Belo Horizonte, v. 29, n. 50, p.453-475, maio/ago., 2013.

RIBEIRO, Darcy. Confissões. 2 ed. São Paulo: Companhia das Letras, 1997.

SAINT-HILAIRE, Auguste. Viagens pelas Províncias do Rio de Janeiro e de Minas Gerais. Belo Horizonte: Itatiaia, 1975.

SANTOS, Rosana de Jesus. Entre elas: a violência de gênero de patroas contra domésticas - Montes Claros, 1961-1980. In: MAIA, Cláudia; CALEIRO, Regina C. (Orgs.) Mulheres, violência e justiça no norte de Minas. São Paulo: Annablume, 2012, p.189-214.

SEGATO, Rita Laura. O Édipo Brasileiro: a dupla negação de gênero e raça. In: STEVENS, Cristina (Org). Maternidade e feminismo: diálogos interdisciplinares. Florianópolis: Ed. Mulheres, 2007, p.141-170.

SCOTT, Joan. Gênero: uma categoria útil de análise histórica. Educação e Realidade, v.20, p.71-100, Jul./Dez.,1995.

SILVEIRA, Yvonne; COLARES, Zéze. Montes Claros de ontem e de hoje. V.1. Montes Claros: Academia Montesclarense de Letras, 1995.

SOIHET, Rachel. Condição feminina e formas de violência: mulheres pobres e ordem urbana 1890-1920. Rio de Janeiro: Forense Universitária, 1989.

SOUZA, Cândice; BOTELHO, Tarcísio Rodrigues. Modelos nacionais e regionais de família no pensamento social brasileiro. Estudos Feministas. Florianópolis, v.9, n.2, 2001.

VASCONCELOS, Diogo. História média de Minas. Belo Horizonte: Imprensa Oficial, 1918. 
Recebido em 15/02/2018 Aprovado em 20/06/2018

Universidade do Estado de Santa Catarina - UDESC

Programa de Pós-Graduação em História - PPGH

Revista Tempo e Argumento Volume 10 - Número 25 - Ano 2018 tempoeargumento@gmail.com 